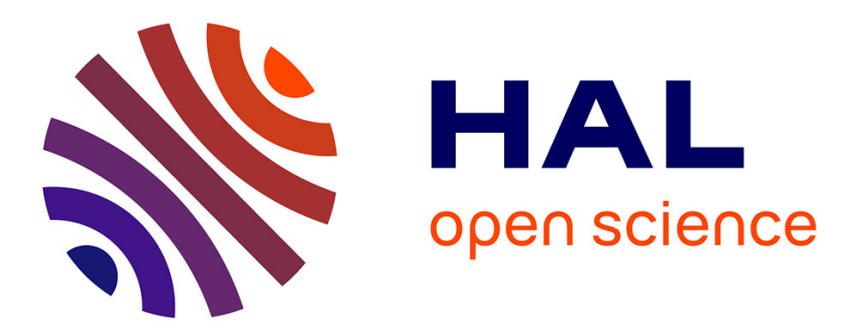

\title{
Influence of injection molding on the electrical properties of polyamide 12 filled with multi-walled carbon nanotubes
}

Sophie Versavaud, Gilles Regnier, Gwénaël Gouadec, Michel Vincent

\section{- To cite this version:}

Sophie Versavaud, Gilles Regnier, Gwénaël Gouadec, Michel Vincent. Influence of injection molding on the electrical properties of polyamide 12 filled with multi-walled carbon nanotubes. Polymer, 2014, 55, pp.6811-6818. 10.1016/j.polymer.2014.10.038 . hal-01096988

\section{HAL Id: hal-01096988 \\ https://hal.science/hal-01096988}

Submitted on 18 Dec 2014

HAL is a multi-disciplinary open access archive for the deposit and dissemination of scientific research documents, whether they are published or not. The documents may come from teaching and research institutions in France or abroad, or from public or private research centers.
L'archive ouverte pluridisciplinaire HAL, est destinée au dépôt et à la diffusion de documents scientifiques de niveau recherche, publiés ou non, émanant des établissements d'enseignement et de recherche français ou étrangers, des laboratoires publics ou privés. 


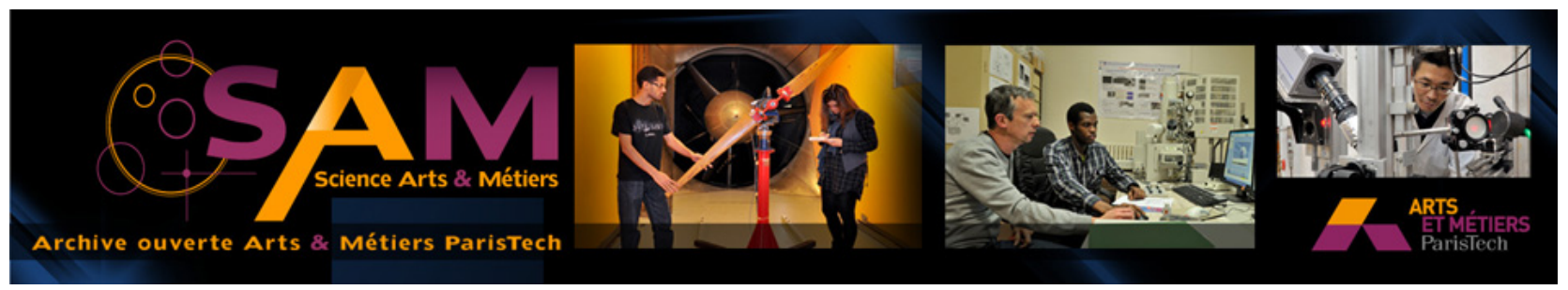

Science Arts \& Métiers (SAM)

is an open access repository that collects the work of Arts et Métiers ParisTech researchers and makes it freely available over the web where possible.

This is an author-deposited version published in: http://sam.ensam.eu

Handle ID: .http://hdl.handle.net/10985/9122

\section{To cite this version :}

Sophie VERSAVAUD, Gilles REGNIER, Gwénaël GOUADEC, Michel VINCENT - Influence of injection molding on the electrical properties of polyamide 12 filled with multi-walled carbon nanotubes - Polymer - Vol. 55, p.6811-6818 - 2014 


\title{
Influence of injection molding on the electrical properties of polyamide 12 filled with multi-walled carbon nanotubes
}

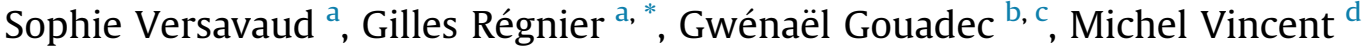 \\ a PIMM, Arts et Métiers ParisTech, CNRS, CNAM, 151 Boulevard de l'Hôpital, 75013 Paris, France \\ b Sorbonne Universités, UPMC Univ Paris 06, UMR 8233, MONARIS, 75005 Paris, France \\ ${ }^{\mathrm{c}}$ CNRS, UMR 8233, MONARIS, 75005 Paris, France \\ d CEMEF UMR 7635, Mines ParisTech, CS 10207, 06904 Sophia Antipolis Cedex, France
}

Keywords:

Polymer-matrix nanocomposites

Electrical properties

Raman spectroscopy

\begin{abstract}
A B S T R A C T
Microinjection-molded and compression-molded polyamide (PA12) matrix composites filled with 0.67 , 1.33, 2 and $4 \mathrm{wt} \%$ multi-walled carbon nanotubes (MWNTs) were prepared from twin-screw extruded pellets. The compression molded samples have an electrical percolation threshold close to $1.2 \mathrm{wt} \%$. Coupled rheological and electrical measurements show that their electrical properties start decreasing as soon as shear begins and are partially restored during flow, suggesting successively breakage and reconstruction of a percolating network. On the other hand, the electrical properties of the microinjection molded composites are close to the matrix ones, showing that cooling is too fast for the MWNTs to form a network. There is some electrical anisotropy in these composites, as evidenced by a greater conductivity measured in the flow direction. However polarized Raman spectroscopy analysis does not reveal a significant orientation of the MWNTs.
\end{abstract}

\section{Introduction}

Multi-walled carbon nanotubes (MWNTs) are assemblies of between 2 and more than 50 coaxial graphene tubes that can be as conductive as copper (between $10^{4}$ and $10^{8} \Omega^{-1} \cdot \mathrm{m}^{-1}$ ), with current densities up to 1000 times higher $\left(10^{13} \mathrm{~A} \cdot \mathrm{m}^{-2}\right)$ [1-3]. MWNTs exhibit low densities $\left(1750 \mathrm{~kg} \cdot \mathrm{m}^{-3}\right)$, aspect ratios as high as 1000:1 $[3,4]$ and are considered as nanofillers because of their small diameter (about $10 \mathrm{~nm}$ ) [1].

The percolation threshold represents a precise MWNTs content beyond which the insulating composite becomes electrically conductive [5-7]. Percolated nanocomposites can reach conductivities in the range of $10^{-5}-100 \Omega^{-1} \cdot \mathrm{m}^{-1}$, comparable to semiconductors, giving them electrostatic discharge and electromagnetic interference shielding properties [8]. The percolation threshold is very low (only a few wt $[2,5,6,9,10]$ compared to $20 \mathrm{wt}$ $\%$ for carbon black [11]) because a high aspect ratio is favorable [11]. In practice, MWNTs are highly flexible, their mutual attraction by Van der Waals forces results in complex microstructures $[9,12]$ and the end properties of filled thermoplastics actually depend on the

\footnotetext{
* Corresponding author.

E-mail address: gilles.regnier@ensam.eu (G. Régnier).
}

dispersion and orientation of the tubes [5,6]. The processing conditions lead to a reduction of the matrix viscosity which favors Van der Waals attractions and therefore MWNTs agglomeration $[13,14]$. Unexpectedly, annealing may increase the electrical conductivity by the formation of a percolation network during MWNTs aggregation [15]. Similar conductivity improvements were reported for a composite subjected to shear [16].

Injection molding is the process offering the best yield for manufacturing thermoplastic products. When used to make composites, the high shear rates and temperature gradients result in particular fillers arrangements [17]. For classical glass or carbon reinforced thermoplastics, a significant fiber orientation prevails in the flow direction at the surface of the parts and often perpendicular to the flow in the core $[17,18]$. In microinjection molding machines with flow gaps less than $0.1 \mathrm{~mm}$, micro or nanometric fillers like carbon nanotubes (CNTs) are expected to replace glass fibers [19]. Microinjection molding implies high shear rates and very fast cooling $[20,21]$. The orientation of MWNTs may be observed by Transmission Electronic Microscopy (TEM) but only if they lie in the plane of the "ultramicrotome" cuts [2,12] and many images are necessary to get a statistics [22]. Raman scattering is an alternative way because its intensity $\left(I_{R}\right)$ depends on the orientation of the scatterer with respect to the polarization of the incident $\left(e_{\mathrm{i}}\right)$ and scattered $\left(e_{s}\right)$ light, via the polarizability tensor $\overline{\bar{\alpha}}[23]$ : 
$I_{\mathrm{R}} \propto\left|\vec{e}_{\mathrm{i}} \overline{\bar{\alpha}} \vec{e}_{\mathrm{s}}\right|^{2}$

Besides, the "double resonance" phenomenon makes Raman scattering extremely sensitive to even the lowest CNTs concentrations [20] and the "antenna effect" reinforces the orientation dependency, the highest intensity being collected for a laser polarized along the tubes axis [24].

This work aimed at investigating the electrical properties of very thin PA12/MWNTs injection molded composites. In a first step, compression molded composites were used as references, assuming that the compression step induces quasi-isotropic samples. Oscillatory shear rheology and electrical properties were measured simultaneously at $220^{\circ} \mathrm{C}$. In a second step, the electrical properties of the injection molded composites were determined at room temperature and polarized Raman spectroscopy experiments were conducted to assess the MWNTs orientation.

\section{Experimental}

\subsection{Materials}

The matrix used in this work is Rilsan ${ }^{\circledR}$ AMNO PA12 injection grade from Arkema. Its Newtonian viscosity is relatively low (150 Pa.s at $220^{\circ} \mathrm{C}$ ). The temperatures of melting, $T_{\mathrm{m}}=178^{\circ} \mathrm{C}$, and approximate crystallization, $T_{\mathrm{C}}=158^{\circ} \mathrm{C}$, were measured by differential scanning calorimetry. The MWNTs were provided by Arkema, in the form of a CM1-20 Graphistrength ${ }^{\circledR}$ masterbatch containing $20 \mathrm{wt} \%$ MWNT dispersed in PA12. As produced, the MWNTs had between 5 and 15 walls, outside diameters in the range of $10-15 \mathrm{~nm}$ and a maximum aspect ratio of 1000:1.

\subsection{Sample preparation}

Composite pellets with $0.67,1.33,2$ and 4 wt\% MWNTs were first prepared by mixing the masterbatch with neat PA12 in a Brabender Plasti-Corder twin-screw extruder. The three heating zones were set at 190,210 and $220^{\circ} \mathrm{C}$ from the hopper to the nozzle. The screw rotation velocity was set at $50 \mathrm{rpm}$. The extrudate was stretched and cut in line with a Brabender Pelletizer CAN-plus. The MWNTs contents were checked by thermogravimetric analysis (TGA) under air flow, from 20 to $600{ }^{\circ} \mathrm{C}$.

Some pellets were placed in a circular $25 \mathrm{~mm}$-diameter 1 or $0.5 \mathrm{~mm}$ thick mold cavity and then compression molded at $220^{\circ} \mathrm{C}$ in a manual DARRAGON press. The discs obtained were kept at $220^{\circ} \mathrm{C}$ for at least $10 \mathrm{~min}$ to avoid any preferential orientation of the MWNTs. Another part of the pellets was injected in a thin plate cavity with an Inserjet machine from Getelec Company (Fig. 1). The cavity was a $25 \mathrm{~mm}$-sided square designed in such a way that the flow front was parallel to the gate channel. Thicknesses of 0.3 and $0.5 \mathrm{~mm}$ were chosen to simulate microinjection geometry. The mold was heated at $100{ }^{\circ} \mathrm{C}$ and the barrel at $220-245-260{ }^{\circ} \mathrm{C}$.

\subsection{Rheological measurements}

Melt rheological properties were measured at $220^{\circ} \mathrm{C}$ in a strain controlled ARES-rheometer (TA-Instruments), using $25 \mathrm{~mm}$ diameter parallel plates. The temperature was set lower than the injection one to save $1800 \mathrm{~s}$ before observing PA12 degradation in rheological measurements. The samples were tested in dynamic mode, the frequency varied from 100 to 0.1 rad.s ${ }^{-1}$ and the strain remained in the linear viscoelastic domain.

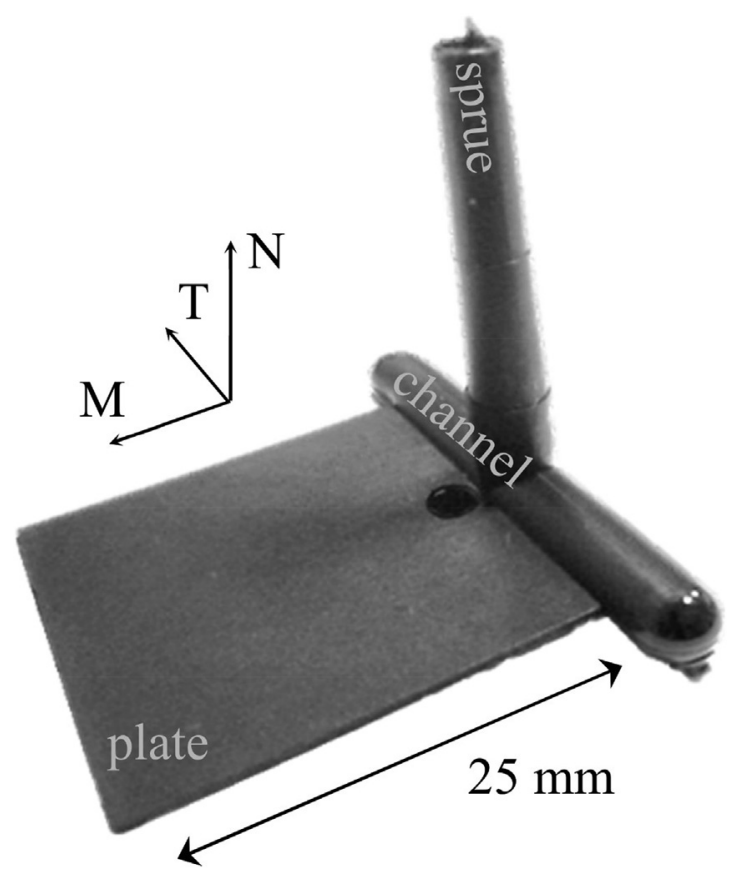

Fig. 1. Injection molded composites. $\mathrm{M}$ direction corresponds to the flow direction, $\mathrm{N}$ direction is normal to the sample plane and $\mathrm{T}$ direction is perpendicular to the other two.

\subsection{Electrical and rheo-electrical measurements}

The direct current conductivity $\left(\sigma_{\mathrm{DC}}\right)$ was measured with a Keithley electrometer $6517 \mathrm{~A}$ and the real part of the complex conductivity $\left(\sigma^{\prime}\right)$ was measured in the range $10^{2}-10^{6} \mathrm{~Hz}$ using an LCR-meter Agilent 4284A. Both apparatuses were connected to $25 \mathrm{~mm}$ diameter steel plates isolated by ceramic rings, which allowed for electrical measurements in the oven of the rheometer. The electrical properties of the composites were measured along the $\mathrm{M}, \mathrm{N}$ and $\mathrm{T}$ directions showed in Fig. 1 , at $23^{\circ} \mathrm{C}$ and $220^{\circ} \mathrm{C}$. Some silver paint was added to ensure a good contact with the steel plates during measurements at room temperature. Coupled rheological and electrical measurements were performed over $1800 \mathrm{~s}$ at $220{ }^{\circ} \mathrm{C}$, with a steady shear rate of either 0.02 or $1 \mathrm{~s}^{-1}$ applied between $t=600 \mathrm{~s}$ and $t=1200 \mathrm{~s}$.

\subsection{Optical microscopy}

Microscopy observations were made in transmission with an Olympus BH-2 UMA optical microscope. The composites were cut into $5 \mu \mathrm{m}$ slices with a Leica RM-2255 microtome.

\subsection{Raman spectroscopy}

The spectra were collected in backscattering configuration on a HR-800 spectrometer (Horiba Scientific), using the $514.5 \mathrm{~nm}$ excitation from an $\mathrm{Ar}^{+}$ion laser and a 600 lines $/ \mathrm{mm}$ grating (resolution around $2 \mathrm{~cm}^{-1}$ ). We mostly used a $50 \times$ magnification SLMP objective (Olympus) with a relatively low numerical aperture (0.45) to limit polarization scrambling [25]. The lateral resolution was about $2 \mu \mathrm{m}$ and we expected to probe a few hundred MWNTs at once. The depth of field was about $5 \mu \mathrm{m}$ but penetration was obviously lowered because of light absorption by the CNTs.

The laser polarization was changed from vertical (V) to horizontal $(\mathrm{H})$ with a $\lambda / 2$ waveplate. The backscattered light was sent 
through a polarizer to select either $\mathrm{V}$ - or H-polarized photons, then through a $\lambda / 2$ waveplate adjusted to always have $V$-polarized light hit the grating. The samples were $0.5 \mathrm{~mm}$-thick injection molded composites cut halfway across T direction with a Leica RM-2255 microtome. They were set in the position illustrated in Fig. 2, standing on a $1^{\circ}$ precision rotating platen.

When the axis of the rotation platen was brought into perfect coincidence with the optical axis of the microscope, a definite spot could be analyzed as a function of the angle $\varphi$ between M direction and the vertical polarization.

\section{Results and discussion}

\subsection{Characterization of the compression-molded reference samples}

\subsubsection{Melt rheological properties}

At $220^{\circ} \mathrm{C}$, neat PA12 exhibits a classical terminal viscoelastic behavior since the storage and loss moduli respectively obey $G^{\prime} \approx \omega^{2}$ and $G^{\prime \prime} \approx \omega^{1}$ laws (Fig. 3a-b). MWNTs addition has a huge effect on rheology, especially at low frequencies, and the values of $G^{\prime}, G^{\prime \prime}$ and the real part of complex viscosity $\eta^{\prime}$ increase by up to five decades for $20 \mathrm{wt} \%$ MWNTs (Fig. 3a-c). For this concentration, $\eta^{\prime}$ follows a power law with -1 exponent value and $G^{\prime}$ is constant, which characterizes a physical gel. The slope changes of $G^{\prime}, G^{\prime \prime}$ and $\eta^{\prime}$ curves between 0.67 and $2 \mathrm{wt} \%$ reveal a liquid to gel transition. As a physical network is formed, the composites are expected to become electrically conductive.

\subsubsection{Electrical properties}

Fig. 4a shows the evolution of $\sigma^{\prime}$ (at $10^{4} \mathrm{~Hz}$ ) and $\sigma_{\mathrm{DC}}$ versus MWNTs content. Since conductivities are high and very close to those of 2 and $4 \mathrm{wt} \%$ contents, the percolation threshold is most likely reached, resulting in tube-to-tube electronic transport. For filler contents below the percolation threshold, an insulating adsorbed polymer layer on the surface of the nanotubes is probably formed, preventing direct electrical contact between the nanotubes [10]. Then the electrical behavior is similar to that of neat PA12 which displays a low conductivity following a classical power law frequency dependence (typical of an insulating material) [5]. The increase measured between $\sigma_{\mathrm{DC}}$ and $\sigma^{\prime}$ (at $10^{4} \mathrm{~Hz}$ ) is consistent with this evolution. In addition, lowering the temperature leads to the crystallization of the matrix and the decrease of $\sigma^{\prime}$. In the case of DC measurements, neat PA12 and the 0.67 wt\% composite have an insulating behavior $\left(\sigma_{\mathrm{DC}} \sim 10^{-12} \Omega^{-1} \cdot \mathrm{m}^{-1}\right)$ and the percolation

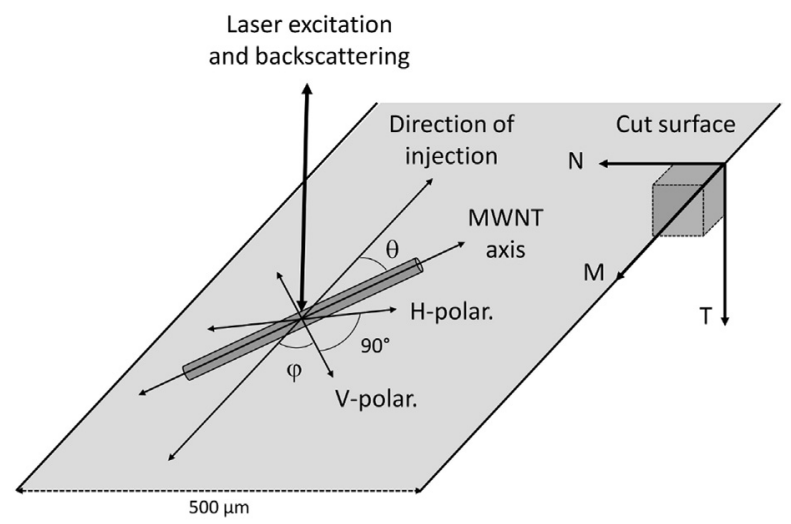

Fig. 2. Raman setup for the analysis of the injection-molded composites. $\varphi$ is the angle between the injection direction (M) and the laser polarization. $\theta$ is the angle between $\mathrm{M}$ direction and a MWNT axis.
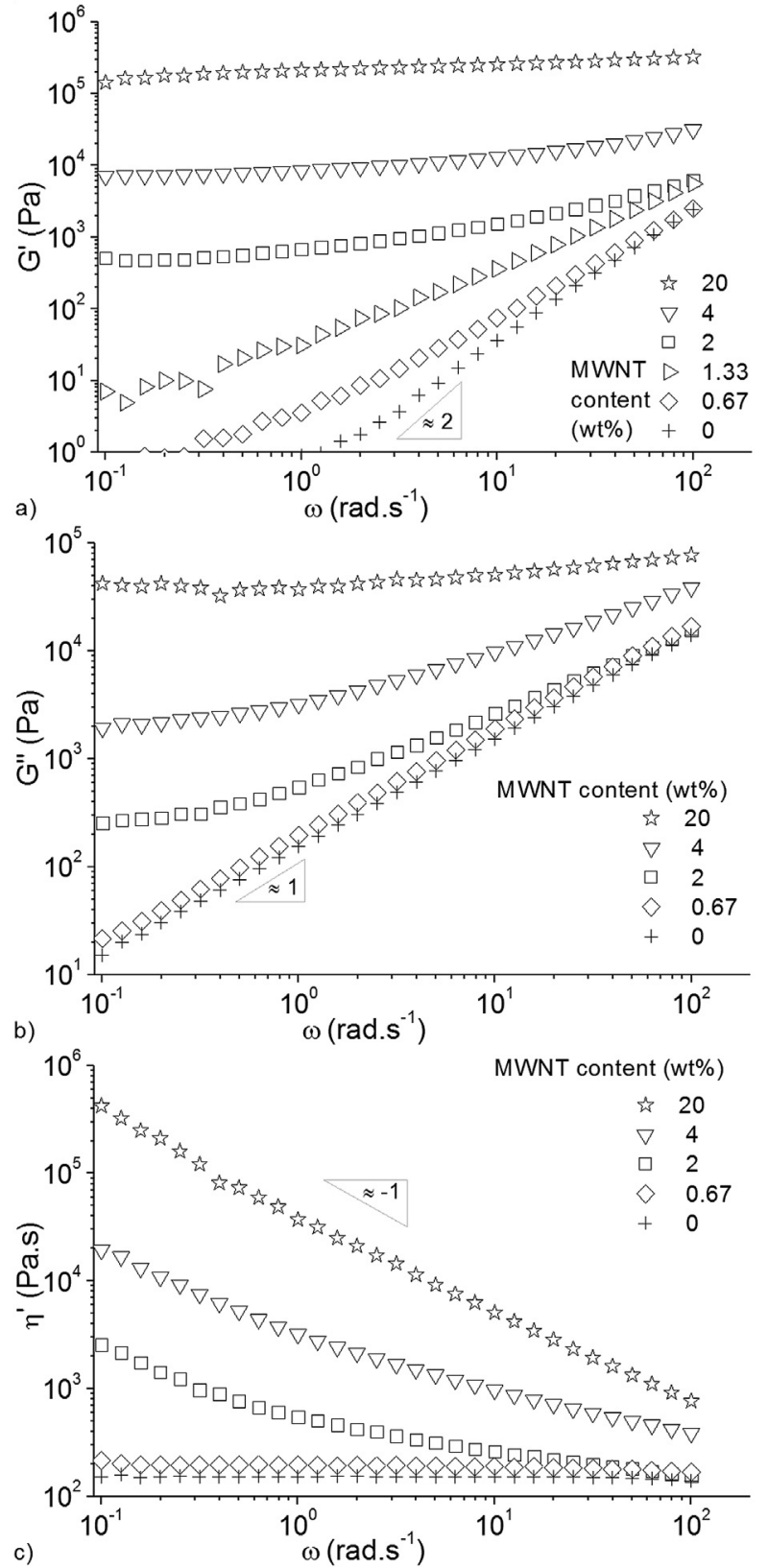

Fig. 3. Variation of a) shear storage modulus, b) shear loss modulus, and c) real part of viscosity in melted PA12/MWNTs compression molded composites $\left(T=220^{\circ} \mathrm{C}\right)$

threshold $p_{\mathrm{c}}$ obviously stands somewhere between $0.67 \mathrm{wt} \%$ and $1.33 \mathrm{wt} \%$. For filler contents above the percolation threshold $p_{\mathrm{c}}$, the percolation theory predicts:

$\sigma_{\mathrm{DC}} \sim\left(p-p_{\mathrm{C}}\right)^{t}$

In our case, the fitted parameters are $p_{c}=1.2 \mathrm{wt} \%$ and $t=3.1$. The critical exponent is higher than the 1.99 value expected for a 3D network [5,7] but similar results were reported for carbon black/ polymer composites [26]. This may be explained by a non random arrangement of the filler such as aggregation into a fractal structure (the theory does not take the structure of the conductive phase into account) [5,9] or by tunneling conduction [26].

Fig. $4 \mathrm{~b}$ compares the electrical loss angle at $23{ }^{\circ} \mathrm{C}$ (measurements at higher temperature are impossible because of thermal agitation) and the rheological phase angle at $220^{\circ} \mathrm{C}$. 


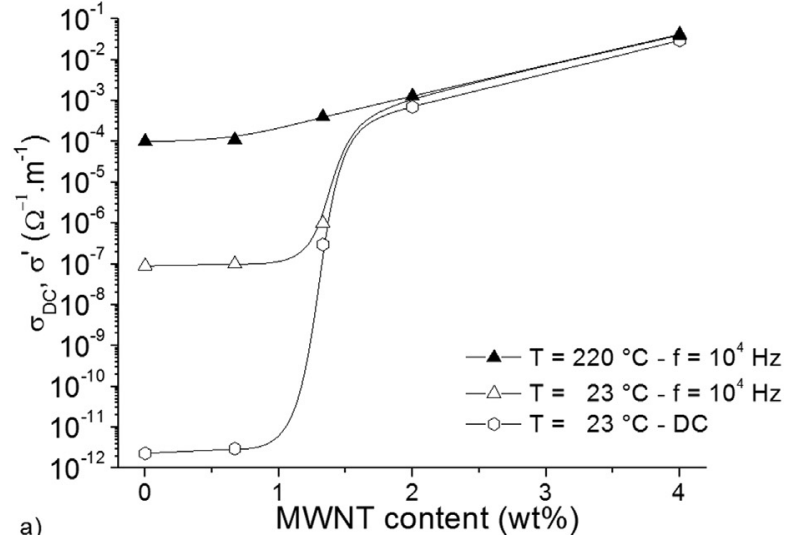

a)

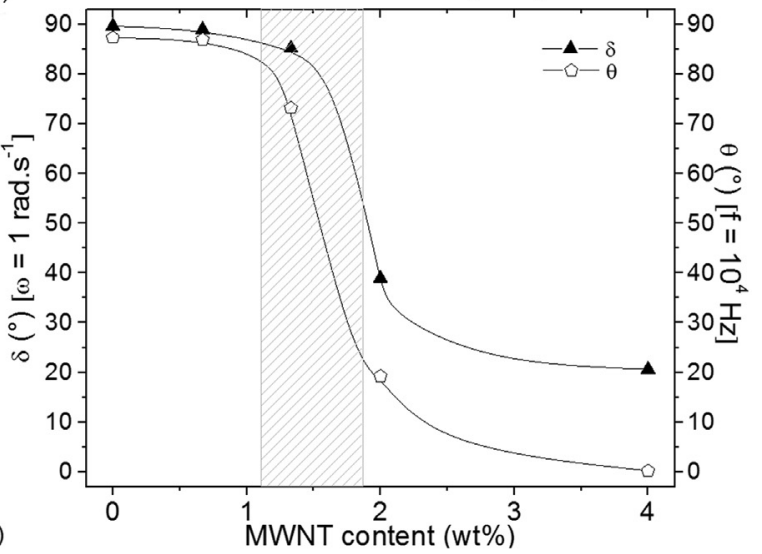

Fig. 4. Variation of a) real part of the complex conductivity $\left(\sigma^{\prime}\right)$ and direct current conductivity $\left(\sigma_{\mathrm{DC}}\right)$ b) loss angle $\delta$ (at $220^{\circ} \mathrm{C}$, for $\omega=1 \mathrm{rad}^{-1} \mathrm{~s}^{-1}$ ) and phase angle $\theta$ (at $23^{\circ} \mathrm{C}$, for $f=10^{4} \mathrm{~Hz}$ ) in compression-molded PA12/MWNTs composites.

\subsection{Shear influence}

Fig. 5 presents the conductivity measured through $\mathrm{N}$ direction during a rheological test of two compression molded composites (filled with 1.33 and $2 \mathrm{wt} \%$ ) at $220^{\circ} \mathrm{C}$.

During the first $600 \mathrm{~s}$, no shear is applied and $\sigma^{\prime}$ increases, meaning new percolation pathways appear through the thickness as a result of a slow process of MWNTs aggregation by van der Waals forces [14]. This phenomenon is more pronounced at $1.33 \mathrm{wt}$ $\%$, which must therefore be very close to the percolation threshold

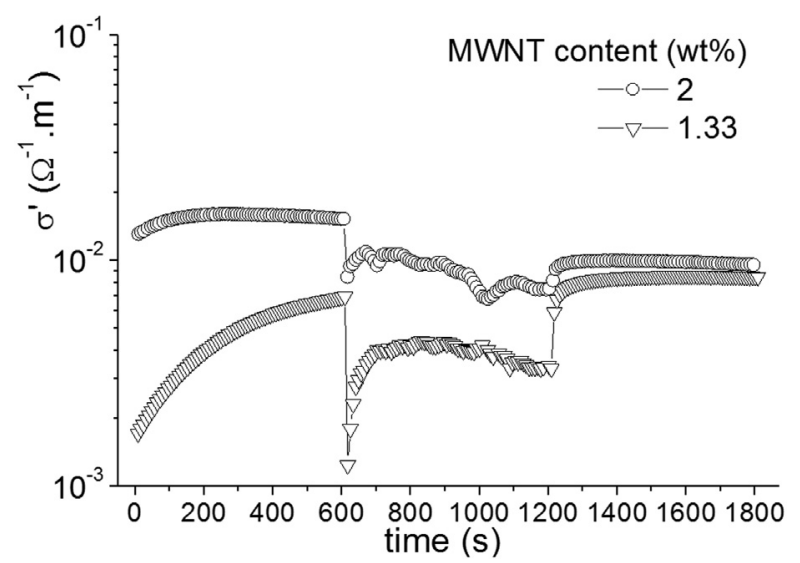

Fig. 5. $\sigma^{\prime}$ evolution measured at $220^{\circ} \mathrm{C}$ for $1.33 \mathrm{wt} \%$ and $2 \mathrm{wt} \%$ MWNT compression molded composites. A shear rate of $1 \mathrm{~s}^{-1}$ was applied between $t=600 \mathrm{~s}$ and $t=1200 \mathrm{~s}$.
[5]. When a shear rate of $1 \mathrm{~s}^{-1}$ is applied during the next $600 \mathrm{~s}$, the percolation pathways, previously created, are destroyed and $\sigma^{\prime}$ depicts a sudden decrease. Under constant shear rate, the motion imposed to single MWNTs and small clusters allows the punctual creation of percolation pathways $[13,16]$. This dynamic percolation leads to an increase of $\sigma^{\prime}$ after several tens of seconds up to the time where percolation pathways are created and destroyed at the same rate. Finally $\sigma^{\prime}$ comes back to its initial value as soon as shear is suppressed and the tubes get in contact in the melt, driven by the van der Waals forces. Those observations are more pronounced for the $1.33 \mathrm{wt} \%$ composite which is closer to the percolation threshold, where the conductivity is quite sensitive to the changes in microstructure. Similar tests were performed with $0.02 \mathrm{~s}^{-1}$ shear rate and $\sigma^{\prime}$ did not display any significant changes whereas rheological measurements evidenced a modification of the MWNTs network. It then appears that the mechanical and electrical networks differ, as already found by Logakis et al. [27].

\subsection{Influence of injection molding on the electrical properties}

Fig. 6 shows that the electrical properties of micro-injected and compression-molded samples are different. In the compressionmolded $0.67 \mathrm{wt} \%$ composite, $\sigma^{\prime}$ increases with the electrical frequency following a power law. According to the percolation theory, this behavior is characteristic of an insulating material [5].

On the contrary, the $4 \mathrm{wt} \%$ compression molded composite exhibits a constant $\sigma^{\prime}$, which is typical of a conductive material. The $1.33 \mathrm{wt} \%$ and $2 \mathrm{wt} \%$ compression molded composites have an intermediate behavior with $\sigma^{\prime}$ being frequency-independent up to a critical value, above which it starts following a power law (Fig. 6a).
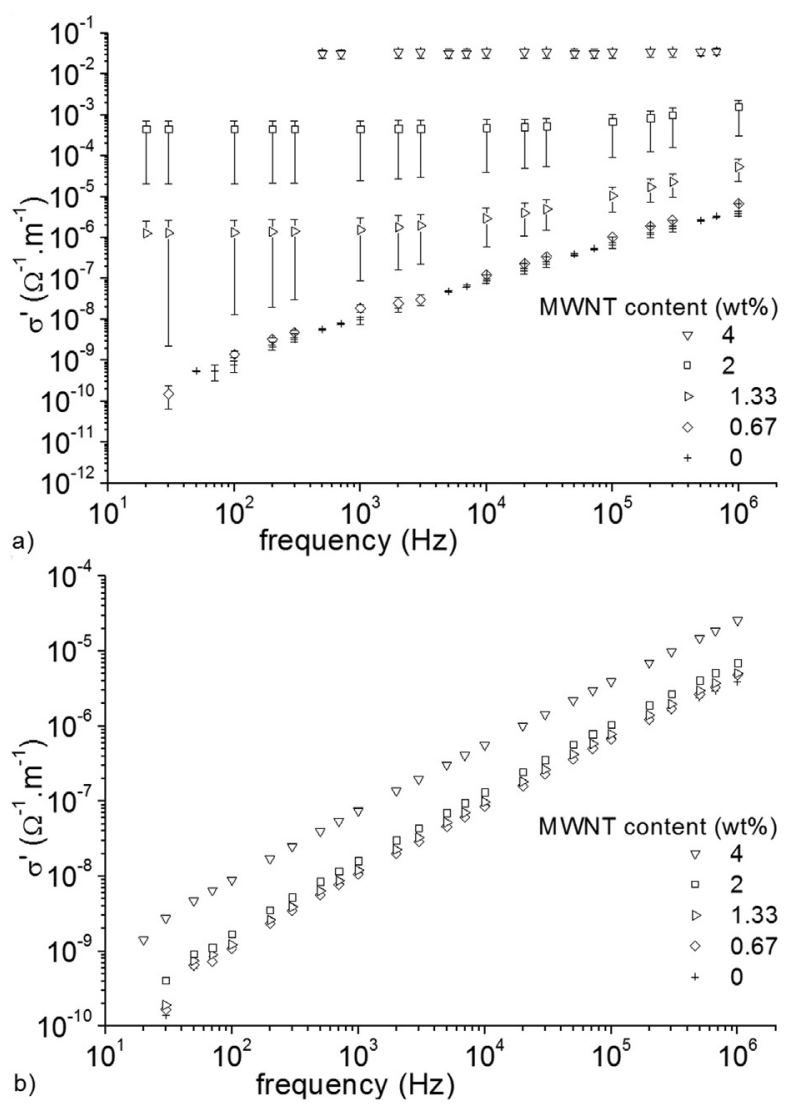

Fig. 6. Effect of frequency on the $\sigma^{\prime}$ value measured at $23^{\circ} \mathrm{C}$ through the $\mathrm{N}$ direction of a) compression molded and b) $0.5 \mathrm{~mm}$-thick injection molded composites. 


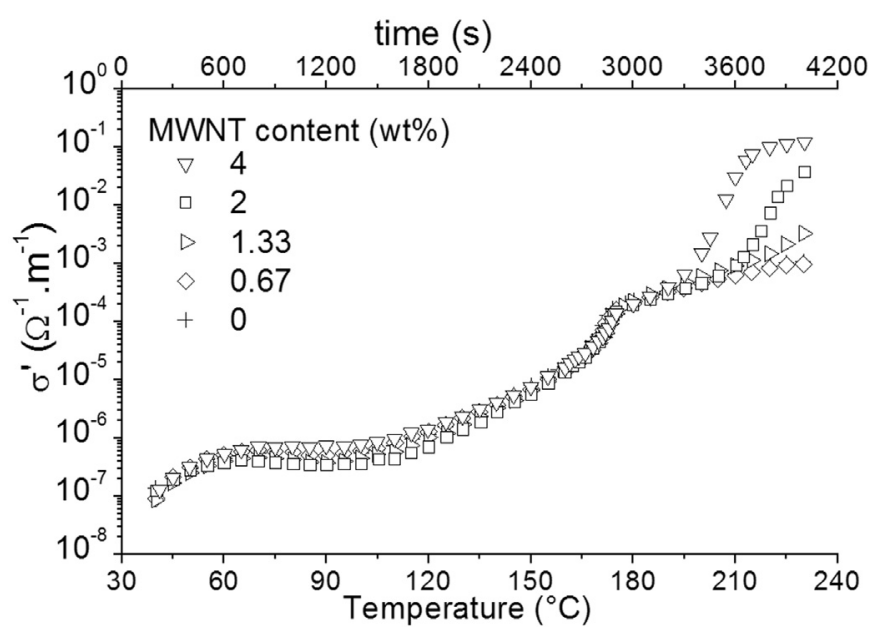

Fig. 7. Evolution of $\sigma^{\prime}$ measured at $10^{4} \mathrm{~Hz}$ between 34 and $230{ }^{\circ} \mathrm{C}$, with a $3{ }^{\circ} \mathrm{C} / \mathrm{min}$ heating rate, through the $\mathrm{N}$ direction of $0.5 \mathrm{~mm}$-thick injection-molded composites.

The conductivities measured through the thickness ( $\mathrm{N}$ direction) of $0.5 \mathrm{~mm}$ thick injected parts all follow power laws (insulating behavior) and the values are close to those of the neat PA 12 polymer (Fig. 6b). Injection molding therefore leads to a complete loss of conductivity in the $\mathrm{N}$ direction. We assume that the high shear rates lead to the rupture of the MWNTs electrical network and that the cooling is too fast to allow dynamic percolation. The electrical properties of the $0.5 \mathrm{~mm}$ thick injected parts were also measured through the $\mathrm{M}$ and $\mathrm{T}$ directions. The values showed a strong anisotropy and a higher conduction in the flow direction, where contacts between MWNTs seem to be statistically favored. A large conductivity difference between $\mathrm{N}$ and $\mathrm{T}$ directions was also observed, which suggests MWNTs orientation is not uniaxial. It can be assumed that the tubes align in the flow plane like fibers do [28]. Electrical properties were also measured on $0.3 \mathrm{~mm}$ thick injected parts. The reduction of thickness from 0.5 to $0.3 \mathrm{~mm}$ leads to a decrease of the conductivity through both $\mathrm{M}$ and $\mathrm{T}$ directions. We assume that a thinner cavity leads to higher shear rates which favors the destruction of the MWNTs network and reduces the number of percolation pathways.

Fig. 7 displays the evolution of $\sigma^{\prime}$ through the thickness of the injected parts during an annealing from $34{ }^{\circ} \mathrm{C}$ to $230{ }^{\circ} \mathrm{C}$ with a heating rate of $3{ }^{\circ} \mathrm{C} / \mathrm{min}$.

In the solid state, all samples display the same insulating behavior and there is a sudden slope change when the melting temperature of PA $12\left(178^{\circ} \mathrm{C}\right)$ is reached. The MWNTs start moving in the melt polymer but percolation pathways do not form instantaneously as it takes several hundred seconds for a conductivity jump to happen. From this point, the values become comparable to those found in hot pressed composites and the greater the MWNTs content, the higher the conductivity. These results confirm that the MWNTs network is destroyed by shear rates during the microinjection process. The MWNTs may end up either isolated or packed in small clusters sufficiently distant from one another to lose the electrical properties.

\subsection{Characterization of the MWNTs arrangement}

Optical microscopy reveals round aggregates with a wide size distribution (the biggest ones reach several micrometers) in the 4 wt\% compression molded composite (Fig. 8a). For the same content, the injected part shows smaller elongated aggregates that seem to orient in the flow direction (Fig. 8b). This observation supports our previous conclusion about the macroscale orientation induced by injection molding. However, we know that percolation pathways exist, at least in the hot pressed composite and the smallest clusters are obviously invisible with optical microscopy $[10,15,22]$.

Preliminary Raman testing evidenced a homogeneous repartition of the MWNTs in the injected parts since a spectrum could be recorded with about the same intensity above any randomly chosen point. However, due to the strong light absorption by the MWNTs, the incident power had to be limited to $500 \mu \mathrm{W}$ not to melt the resin. This rose the recording time to several minutes and limited the analysis to a few points per composite. Fig. 9 shows typical examples of recorded Raman spectra. The resin was responsible for a strong fluorescence background and a Raman contribution partly overlapping with that from the MWNTs (Fig. 9a). Fig. 9b illustrates the procedure used to fit the spectra: all obvious contributions were assigned Lorentzian lineshapes (with the exception of $\mathrm{D}^{\prime}$ band set as Gaussian) and two Gaussian contributions (hatched in Fig. 9b) were added to account for the background. For the procedure equally applied to all composites, the weakest resin contributions were eventually omitted and the positions of $G$ and $D^{\prime}$ bands, the $\sim 1642 \mathrm{~cm}^{-1}$ line as well as the widths of the MWNTs contributions (D, G and $D^{\prime}$ bands) were all set to their fitted values in the $4 \mathrm{wt} \%$ injected part. Lastly, the Gaussian, appearing around $1560 \mathrm{~cm}^{-1}$ at the bottom of Fig. 9b, was moved to $1490 \mathrm{~cm}^{-1}$ to account for the actual background in composites.

Fig. 10 shows $I_{\mathrm{HH}} / I_{\mathrm{VV}}$ ratios measured for $\mathrm{D}$ and $\mathrm{G}$ bands. The intensity adjustments are certainly more reliable for $\mathrm{D}$ band than for $\mathrm{G}$ (overlapping with $\mathrm{D}^{\prime}$ ) but the former is known to result from an electronic resonance [29] and may therefore not be interpreted as easily. No matter which band is considered yet, the conclusions are qualitatively the same.

For sample geometry reasons, the $I_{\mathrm{HH}}$ and $I_{V V}$ values should be the same for a $\varphi$ angle of $45^{\circ}$ and their ratio is indeed close to one.

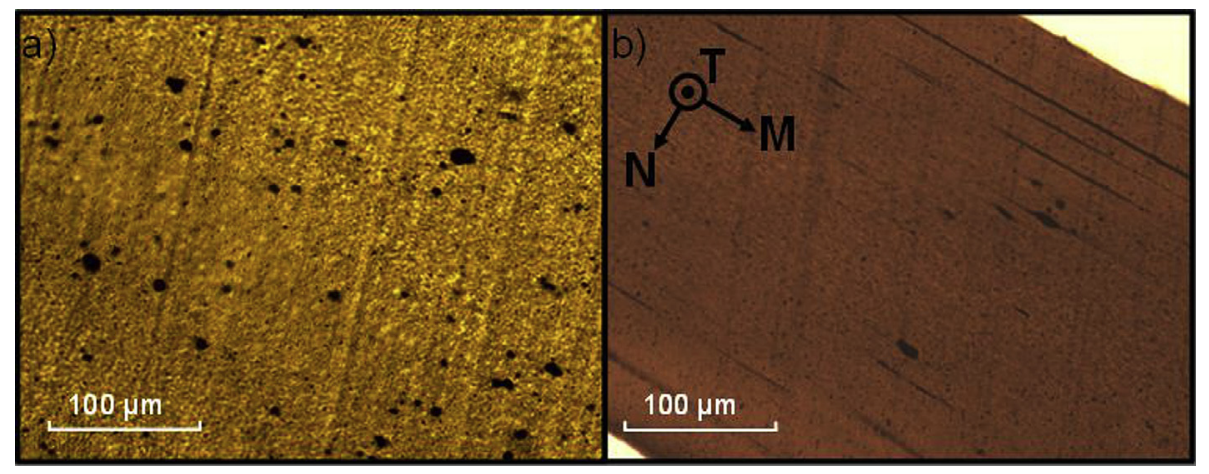

Fig. 8. Optical micrographs of a) compression-molded and b) microinjection-molded PA 12 polymer filled with 4 wt\% MWNTs. 

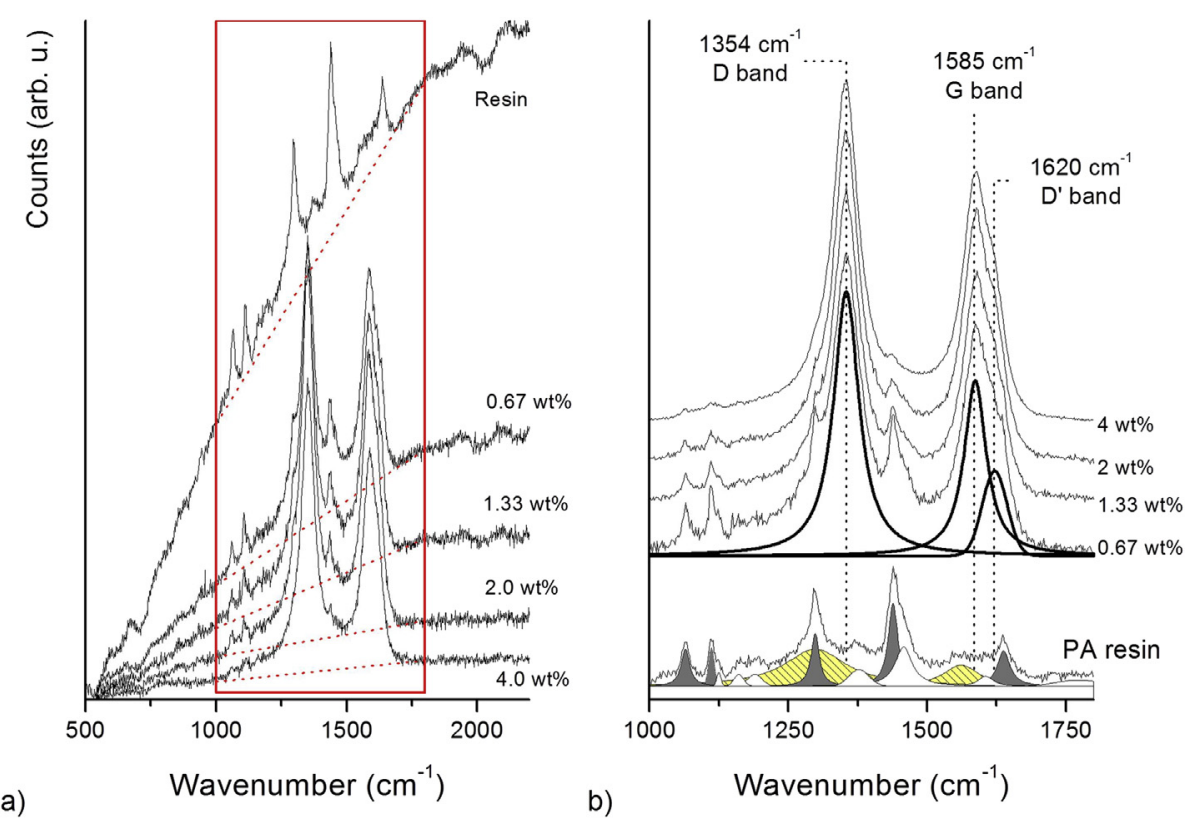

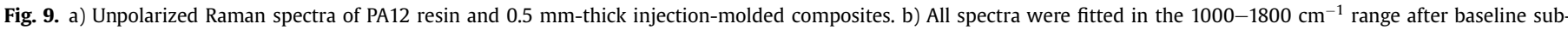
traction (dotted lines in Fig. 9a). Bold lines show D, G and D' bands in the 0.67 wt\% MWNTs composite after removal of the resin contribution (bottom, see details in text))

For $\varphi$ equal to $0^{\circ}$, the $\mathrm{V}$ and $\mathrm{H}$ directions correspond to $\mathrm{M}$ and $\mathrm{N}$ directions, respectively. A 1:1 ratio would correspond to perfect isotropy and the lower values that we obtained indicate some level of preferential orientation along the M direction. Very interestingly, the slope of the interpolated intensity ratio versus MWNTs concentration curves clearly changes around $1.5-1.8 \mathrm{wt} \%$, close to the percolation threshold observed in Fig. 4. The $0.67 \mathrm{wt} \%$ sample being the one with the strongest apparent "orientational anisotropy", we recorded $\mathrm{IVV}_{\mathrm{V}}$ spectra over a randomly chosen point, as a function of $\varphi$ angle (Fig. 11). We used a $50 \times$ magnification 0.75 numerical aperture UIS2 objective (Olympus), which offered a good collection of the backscattered light - hence good quality spectra - but was anticipated to generate some polarization scrambling. Although $I_{\mathrm{Vv}}(\varphi)$ does not vary by more than $\sim 20-25 \%$, its profile

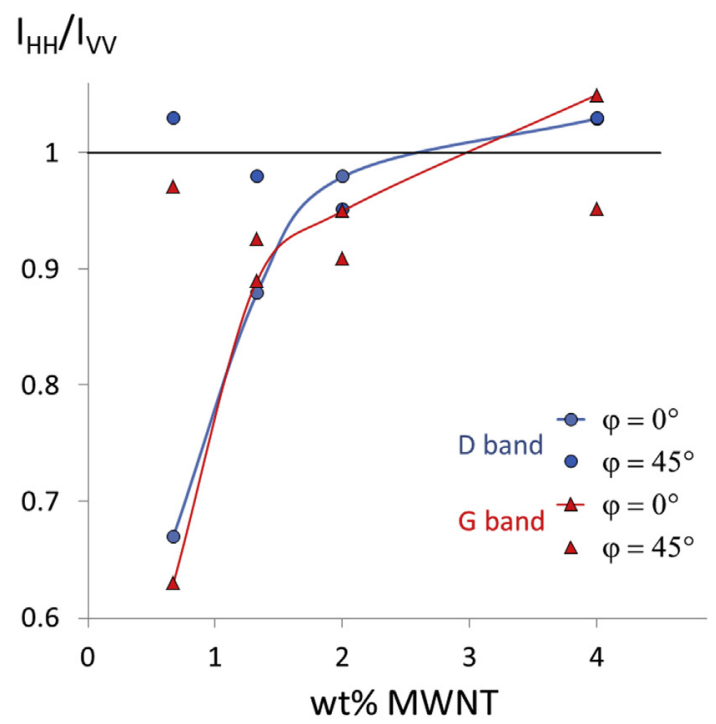

Fig. 10. $I_{\mathrm{HH}} / I_{\mathrm{VV}}$ ratios measured for $\varphi=0$ and $45^{\circ}$ in the middle of the injected parts. unambiguously confirms the orientational anisotropy ( $I_{\mathrm{VV}}$ would be perfectly constant for the isotropic case). Note that all points correspond to a single point of analysis but were normalized as three different series because we slightly refocused the microscope after each $90^{\circ}$ rotation. The data were fitted with the theoretical formalism of Liu and Kumar [30] and used to calculate the Orientation Distribution Function (ODF) (provided as Supplementary Material). The ODF confirms the preferential orientation of the MWNTs in the injection direction but shows quite a significant proportion of nanotubes (about half as many) having transverse orientation. The raw results should obviously be considered with care because the model makes strong assumptions on the symmetries of the MWNTs (perfect cylinders), the ODF (uniaxial) and the Raman tensor (cylindrical) and because of the experimental

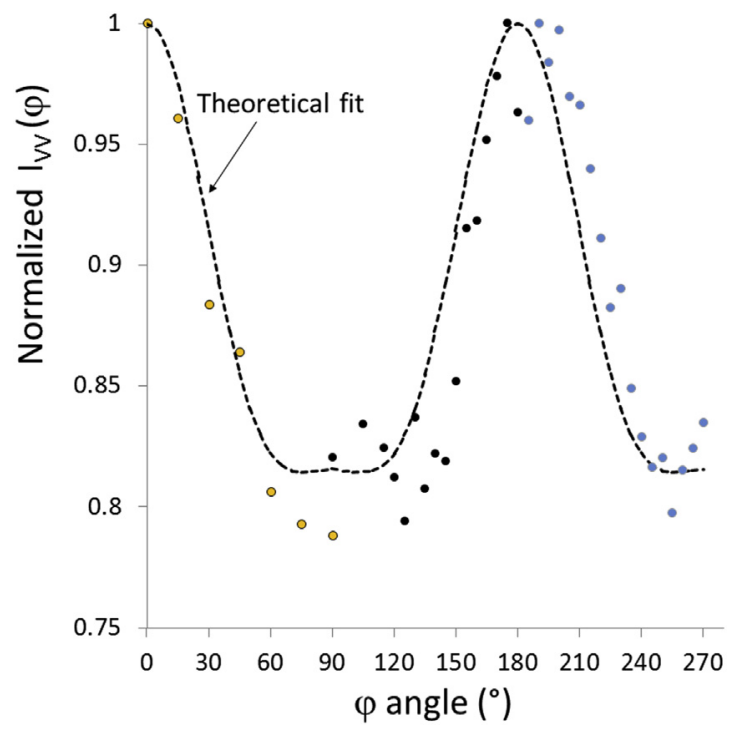

Fig. 11. Normalized values of $I_{\mathrm{VV}}(\varphi)$ for the D-band of MWNTs in the $0.67 \mathrm{wt} \%$ injection-molded composite. 


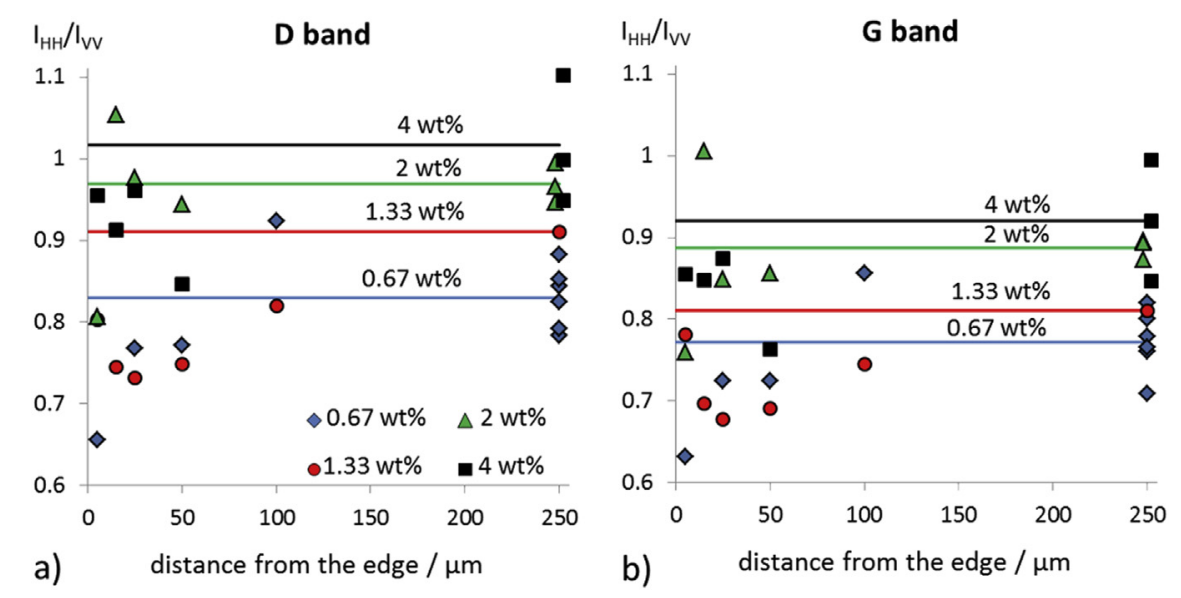

Fig. 12. $I_{\mathrm{HH}} / I_{\mathrm{VV}}$ ratios measured for $\varphi=0^{\circ}$ as a function of the distance to the edge of the sample. The horizontal lines show the average values at the centers $(d \sim 250 \mu \mathrm{m})$.

errors (due to focus variations, fluorescence background and polarization scrambling). However, Raman spectra seem to reveal only a slight orientational anisotropy. The discrepancy between the presumed MWNTs orientation obtained from the electrical and Raman measurements is due to the very different scales involved. In fact, the few cubic micrometers analyzed during Raman measurements only probe the slight orientational anisotropy found locally, at the MWNTs scale, rather than the overall elongation of the MWNTs clusters.

Fig. 12 shows the $I_{\mathrm{HH}} / I_{\mathrm{VV}}$ ratios measured at different distances from the edge of the samples for $\varphi$ angle equal to $0^{\circ}$.

There is some scattering but the average values at $d=250 \mu \mathrm{m}$ are in reasonable agreement with those from Fig. 10. The orientational anisotropy tends to be higher (lower $I_{\mathrm{HH}} / I_{\mathrm{VV}}$ values) in the first 100 microns from the surface, in agreement with assumed higher shear rates. Furthermore, the weakest intensity ratios are found for the composites displaying the weakest MWNTs contents. This point suggests that MWNTs tend to align in the injection direction for low contents but entangle when their probability of making contact gets higher.

\section{Conclusions}

The rheological and electrical properties of compression and injection molded PA12/MWNTs composites were investigated. In the tested frequency range, the rheological properties of the compression-molded samples change from liquid-like to rubberylike when MWNTs are added to the resin, meaning a physical network forms and explaining why the electrical properties drastically improve above the percolation threshold. Coupled rheological and electrical measurements show a conductivity drop as soon as shear begins and partial recovery after several tens of seconds. This suggests that the MWNTs network first breaks and partially rebuilds afterwards. The electrical and rheological percolation thresholds are identical but the electrical conductivity jump is highly reduced at high temperature.

Room temperature measurements evidenced a complete loss of conductivity through the thickness of the injection-molded composites, with values close to the neat matrix ones. High shear stresses break the MWNTs network during the injection and cooling is obviously too fast to allow later reformation. Better electric properties were measured through the other directions, especially in the flow direction. Polarized Raman spectroscopy reveals a slight orientational anisotropy of MWNTs but only under the percolation threshold and mostly in the composites skin, where the shear forces are assumed to peak. In fact, injection molding induces an overall macroscale elongation of the MWNTs clusters, as observed by optical microscopy, whereas only a slight orientational anisotropy is found locally, inside a cluster, by Raman measurements. The shear rates applied during injection molding affect the microstructure of the aggregates. Hence the final electrical properties of injected parts seem to be mainly dominated by the arrangement of the aggregates.

\section{Acknowledgments}

This work was funded by the InterCarnot MICROPOL-29 project. We would like to thank Jérôme Heiligenstein (CryoCapCell company), Patrice Bourson (LMOPS, University of Metz) and Pascale Gemeiner (SPMS, Ecole Centrale de Paris) for helpful discussion and the Arkema company for providing PA12 matrix and CM1-20 masterbatch.

\section{Appendix A. Supplementary data}

Supplementary data related to this article can be found online at http://dx.doi.org/10.1016/j.polymer.2014.10.038.

\section{References}

[1] Iijima S. Helical microtubules of graphitic carbon. Nature 1991;354(6348): $56-8$.

[2] Grossiord N, Loos J, Van Laake L, Maugey M, Zakri C, Koning CE, et al. Highconductivity polymer nanocomposites obtained by tailoring the characteristics of carbon nanotube fillers. Adv Funct Mater 2008;18(20):3226-34.

[3] Xie XL, Mai YW, Zhou XP. Dispersion and alignment of carbon nanotubes in polymer matrix: a review. Mater Sci Eng R Rep 2005;49(4):89-112.

[4] Shaffer MSP, Windle AH. Fabrication and characterization of carbon nanotube/ poly(vinyl alcohol) composites. Adv Mater 1999;11(11):937-41.

[5] Pötschke P, Dudkin SM, Alig I. Dielectric spectroscopy on melt processed polycarbonate - multiwalled carbon nanotube composites. Polymer 2003;44(17):5023-30.

[6] Bauhofer W, Kovacs JZ. A review and analysis of electrical percolation in carbon nanotube polymer composites. Compos Sci Technol 2009;69(10): 1486-98.

[7] Bowen CR, Almond DP. Modelling the 'universal' dielectric response in heterogeneous materials using microstructural electrical networks. Mater Sci Technol 2006;22(6):719-24.

[8] Moniruzzaman M, Winey KI. Polymer nanocomposites containing carbon nanotubes. Macromolecules 2006;39(16):5194-205.

[9] Dalmas F, Dendievel R, Chazeau L, Cavaillé JY, Gauthier C. Carbon nanotubefilled polymer composites. Numerical simulation of electrical conductivity in three-dimensional entangled fibrous networks. Acta Mater 2006;54(11): 2923-31. 
[10] Alig I, Lellinger D, Dudkin SM, Pötschke P. Conductivity spectroscopy on melt processed polypropylene-multiwalled carbon nanotube composites: recovery after shear and crystallization. Polymer 2007;48(4):1020-9.

[11] El Bounia NE, Piccione PM. Experimental investigation of the rheological and electrical properties of poly(vinylidene fluoride) composites based on carbon black and carbon nanotubes synergy. J Polym Eng 2008;28(3):141-54.

[12] Pötschke P, Bhattacharyya AR, Janke A. Melt mixing of polycarbonate with multiwalled carbon nanotubes: microscopic studies on the state of dispersion. Eur Polym J 2004:40(1):137-48.

[13] Pegel S, Pötschke P, Petzold G, Alig I, Dudkin SM, Lellinger D. Dispersion, agglomeration, and network formation of multiwalled carbon nanotubes in polycarbonate melts. Polymer 2008;49(4):974-84.

[14] Pötschke P, Abdel-Goad M, Alig I, Dudkin S, Lellinger D. Rheological and dielectrical characterization of melt mixed polycarbonate-multiwalled carbon nanotube composites. Polymer 2004;45(26):8863-70.

[15] Alig I, Skipa T, Engel M, Lellinger D, Pegel S, Pötschke P. Electrical conductivity recovery in carbon nanotube-polymer composites after transient shear. Phys Status Solidi (B) Basic Res 2007;244(11):4223-6.

[16] Skipa T, Lellinger D, Saphiannikova M, Alig I. Shear-stimulated formation of multi-wall carbon nanotube networks in polymer melts. Phys Status Solidi (B) Basic Res 2009;246(11-12):2453-6.

[17] Vincent M, Giroud T, Clarke A, Eberhardt C. Description and modeling of fiber orientation in injection molding of fiber reinforced thermoplastics. Polymer 2005;46(17):6719-25.

[18] Bay RS, Tucker CL. Fiber orientation in simple injection moldings. Part 2experimental results. Polymer Composites 1992;13(4):332-41.

[19] Giboz J, Copponnex T, Mélé P. Microinjection molding of thermoplastic polymers: a review. J Micromech Microeng 2007;17(6):R96-109.
[20] Abbasi S, Carreau PJ, Derdouri A. Flow induced orientation of multiwalled carbon nanotubes in polycarbonate nanocomposites: rheology, conductivity and mechanical properties. Polymer 2010;51(4):922-35.

[21] Mnekbi C, Vincent M, Agassant JF. Polymer rheology at high shear rate for microinjection moulding. Int J Mater Form 2010;3(Suppl. 1):539-42.

[22] Pegel S, Pötschke P, Villmow T, Stoyan D, Heinrich G. Spatial statistics of carbon nanotube polymer composites. Polymer 2009;50(9):2123-32.

[23] Loudon R. The Raman effect in crystals. Adv Phys 1964;13(52):423-82.

[24] Kempa K, Rybczynski J, Huang Z, Gregorczyk K, Vidan A, Kimball B, et al Carbon nanotubes as optical Antennae. Adv Mater 2007;19(3):421-6.

[25] Turrell G. Analysis of polarization measurements in Raman microspectroscopy. J Raman Spectrosc 1984;15(2):103-8.

[26] Ezquerra TA, Connor MT, Roy S, Kulescza M, Fernandes-Nascimento J, BaltáCalleja FJ. Alternating-current electrical properties of graphite, carbon-black and carbon-fiber polymeric composites. Compos Sci Technol 2001;61(6): 903-9.

[27] Logakis E, Pandis C, Peoglos V, Pissis P, Pionteck J, Pötschke P, et al. Electrical dielectric properties and conduction mechanism in melt processed polyamide/multi-walled carbon nanotubes composites. Polymer 2009;50(21): 5103-11.

[28] Dray D, Gilormini P, Régnier G. Comparison of several closure approximations for evaluating the thermoelastic properties of an injection molded short-fiber composite. Compos Sci Technol 2007;67(7-8):1601-10.

[29] Thomsen C, Reich S. Double resonant Raman scattering in graphite. Phys Rev Lett $2000 ; 85(24): 5214-7$

[30] Liu T, Kumar S. Quantitative characterization of SWNT orientation by polarized raman spectroscopy. Chem Phys Lett 2003;378(3-4):257-62. 